\title{
A IMPORTÂNCIA DA IRRIGAÇÃO EM PEQUENAS E MÉDIAS PROPRIEDADES DA REGIÃO DE PRESIDENTE PRUDENTE-SP
}

\author{
Daniel dos Santos Viais Neto ${ }^{1}$
}

Diana Demarchi ${ }^{2}$

Luís Roberto Almeida Gabriel Filho

RESUMO: Uma A produção de alimentos é uma atividade essencial para a existência humana que demanda efetivamente muita água. A chuva é a sua principal fonte e, na falta desta, a irrigação supre essa necessidade, de forma parcial ou integral. A proposta do presente trabalho é levantar informações quantitativas e qualitativas a respeito de pequenas e médias propriedades da região de Presidente Prudente - SP que praticam a agricultura irrigada e apresentar, com base nos dados obtidos em pesquisa de campo, a importância da irrigação na região. Nesta pesquisa, no total foram entrevistados 28 produtores da região. Quanto à gestão do sistema, a pesquisa mostrou que poucos produtores detêm conhecimento e controle de informações para avaliar o incremento em relação à produtividade e a renda. Custos de implantação e manutenção dos sistemas, custo com energia elétrica e dificuldades com reposição de peças desgastadas e/ou danificadas, são apontadas como entraves no processo produtivo quando se utiliza algum sistema de irrigação. Já em relação ao grau de satisfação dos produtores quanto aos sistemas de irrigação que se encontram instalados em suas propriedades, o resultado é bastante positivo. Além do aumento de produtividade e aumento de renda, os produtores pontuaram benefícios tais como a possibilidade de

\footnotetext{
${ }^{1}$ Licenciado e Bacharel em Matemática (ICMC/USP), Mestre em Matemática Pura (ICMC/USP), Professor Associado da FATEC - Presidente Prudente. dvneto@fatecpp.edu.br.

2 Tecnólogo em Agronegócio, FATEC - Presidente Prudente.diana_demarchi@hotmail.com.

${ }^{3}$ Licenciado em Matemática (FCT/UNESP), Mestre em Matemática Pura (ICMC/USP), Doutor em Agronomia/Energia na Agricultura (FCA/UNESP) e Pós-doutor em Agronomia/Energia na Agricultura (FCA/UNESP), Professor Assistente Doutor da CET/UNESP - Tupã/SP. gabrielfilho@tupa.unesp.br.
} 
sustentar suas famílias com uma pequena área de plantio, a permanência do homem no campo e a possibilidade de produzir em épocas de seca.

Palavras-chave: Grau de satisfação. Produtividade. Rentabilidade.

\section{INTRODUÇÃO}

A água é o elemento fundamental para a existência da vida na Terra. Todos os seres vivos dependem dela para sobreviver e para garantir a permanência da espécie. Além disso, Souza (2009) afirma que a água tem diversas utilidades ao homem como, por exemplo, para a irrigação na agricultura, a indústria, o uso doméstico, a pesca, a geração de energia; também para atrair o turismo, e como gerenciadora de empregos na infraestrutura e de sua distribuição.

De acordo com Rodrigues \& Irias (2004), de todos os possíveis usos da água doce, os usos agrícolas são os que requerem maior volume de água. Segundo o Plano Nacional de Recursos Hídricos (2006), 69\% da água consumida no Brasil têm utilização na agricultura irrigada, com eficiência média de $64 \%$, ou seja, $36 \%$ da água derivada para a irrigação no país constituem-se em perdas por condução e por distribuição nas infraestruturas hidráulicas, provocando um grande desperdício no uso da água na agricultura. Apesar das novas tecnologias, modernos equipamentos e técnicos especializados, o Brasil tem avançado lentamente nas questões do manejo da irrigação e do uso racional da água.

A produção de alimentos é uma atividade essencial para a existência humana que demanda efetivamente muita água. A chuva é a sua principal fonte e, na falta desta, a irrigação supre essa necessidade, de forma parcial ou integral, dependendo da região do país (TESTEZLAF et al., 2002).

Segundo Ricci (2010), a irrigação se configura como o ponto de equilíbrio entre a demanda humana por alimentos, a ocupação ou não de novas terras para agricultura e a preservação da biodiversidade. Mantovani (2008) diz que, em uma visão mais atual, dentro de um foco empresarial dos agronegócios, a irrigação é uma estratégia para aumento da rentabilidade da propriedade agrícola pelo aumento da produção e da 
produtividade, de forma sustentável (preservando o meio ambiente) e com maior geração de emprego e renda, dando enfoque para as cadeias produtivas.

A irrigação é dividida nos seguintes tipos: irrigação por superfície, irrigação por aspersão e irrigação localizada e, de acordo com Mantovani et al. (2009), esses métodos ainda se subdividem. Pires et al. (2008) discorrem que não há um método que seja considerado ideal, e sim aquele que melhor se adapte às condições locais de topografia, clima, tipo de solo e de cultivo, disponibilidade e qualidade da água, mão de obra e energia.

Diante do exposto, a proposta do presente trabalho é levantar informações quantitativas e qualitativas a respeito de pequenas e médias propriedades da região de Presidente Prudente - SP que praticam a agricultura irrigada e apresentar, com base nos dados obtidos em pesquisa de campo, a importância da irrigação na região.

\section{METODOLOGIA}

A Para demonstrar a importância da irrigação em pequenas e médias propriedades da região de Presidente Prudente, realizou-se uma pesquisa de campo quantitativa e qualitativa por meio de entrevistas e preenchimento de questionários. A elaboração dos questionários visou obter respostas que venham de encontro com a proposta deste trabalho, ou seja, colher informações técnicas e dados referentes à satisfação de produtores que praticam a agricultura irrigada. As entrevistas e a aplicação dos questionários aos produtores foram realizadas em feiras livres e em propriedades rurais durante um período de 5 semanas, entre os dias 12/05/2012 e 09/06/2012

O questionário aplicado na pesquisa é composto de oito tópicos, a saber:

- Identificação da propriedade;

- Cultura e área irrigada;

- Fontes de energia;

- Tempo de irrigação;

- Fontes de água utilizada;

- Consumo de água; 
- Gestão do sistema;

- Outras informações.

Após a aplicação dos questionários, os dados foram tabulados e analisados por meio de elementos da estatística descritiva. Foram utilizados gráficos de setores, elaborados no programa Microsoft Excel, para apresentar alguns resultados auferidos na pesquisa. A amostra utilizada nesta pesquisa foi uma Amostra Não-Aleatória, mais especificamente uma Amostra por Conveniência, ou seja, aquela em que os membros mais acessíveis da população são selecionados de maneira à rapidamente obter os resultados (MANN, 2006).

\section{RESULTADOS E DISCUSSÃO}

A pesquisa de campo colheu informações técnicas e dados referentes à satisfação de 28 produtores da região de Presidente Prudente.

Em relação ao tamanho das propriedades pesquisadas, os números ficaram entre 0,1 ha $\left(1.000 \mathrm{~m}^{2}\right)$ e 1.936 ha $\left(19.360 .000 \mathrm{~m}^{2}\right)$. Levando-se em consideração somente as áreas irrigadas destas propriedades, os números variam entre 0,1 ha $\left(1.000 \mathrm{~m}^{2}\right)$ e 217,8 ha $\left(2.178 .000 \mathrm{~m}^{2}\right)$. Quanto à localização, constam as seguintes cidades: Presidente Prudente, Alvares Machado, Alfredo Marcondes, Pirapozinho, Marabá Paulista, Santo Expedito, Narandiba, Martinópolis, Santo Anastácio e Ribeirão dos Índios.

Em meio às variedades cultivadas com o uso da irrigação, ganha destaque a olericultura, com a produção de alface, rúcula, almeirão, couve, coentro, salsa, cebolinha, agrião, acelga, rabanete, beterraba, cenoura, jiló, berinjela, vagem, brócolis, pimentão, couve-flor, repolho e pimenta. As frutas como banana, macadâmia, coco, uva, amora e pitaya também aparecem como culturas irrigadas. As maiores propriedades cultivam pepino para conserva, tomate, cana-de-açúcar, milho, feijão e algodão. Além disso, várias propriedades utilizam irrigação na produção de pastagem para gado de corte e gado leiteiro.

Quanto aos sistemas utilizados, o mais empregado é o sistema por aspersão, principalmente o convencional, por conta do cultivo das hortaliças. Conforme declaração 
dos produtores, a utilização de irrigação nesse tipo de produção é indispensável, principalmente no cultivo de verduras, uma vez que só há produtividade se a cultura for irrigada. Em segundo lugar aparece o sistema de irrigação localizada, com destaque para o gotejamento, cujo sistema apresenta aspectos positivos como aproveitamento da água pelas culturas e baixo desperdício pela absorção do solo e evaporação. Nas maiores áreas irrigadas, como as de cana-de-açúcar, milho, feijão e algodão, os proprietários utilizam o sistema de irrigação por pivô central, sistema esse característico de produção em maior escala. Além disso, em algumas propriedades, percebe-se que produtores têm dificuldade em conciliar o sistema de irrigação à cultura. Por exemplo, os que plantam alface e pimentão utilizam-se do sistema de aspersão para irrigar ambas as culturas, quando o correto para o pimentão seria empregar o sistema de gotejamento, já que o mesmo não necessita de água em suas folhas e sim em suas raízes. Os produtores admitem o problema, porém não resolvem por conta do custo de instalação e manutenção de dois sistemas de irrigação.

A respeito da fonte de energia utilizada pelos sistemas de irrigação, 26 propriedades fazem uso de energia elétrica para conduzir a água de sua origem até o plantio. As 2 propriedades restantes utilizam combustíveis, especificamente o diesel (Figura 1).

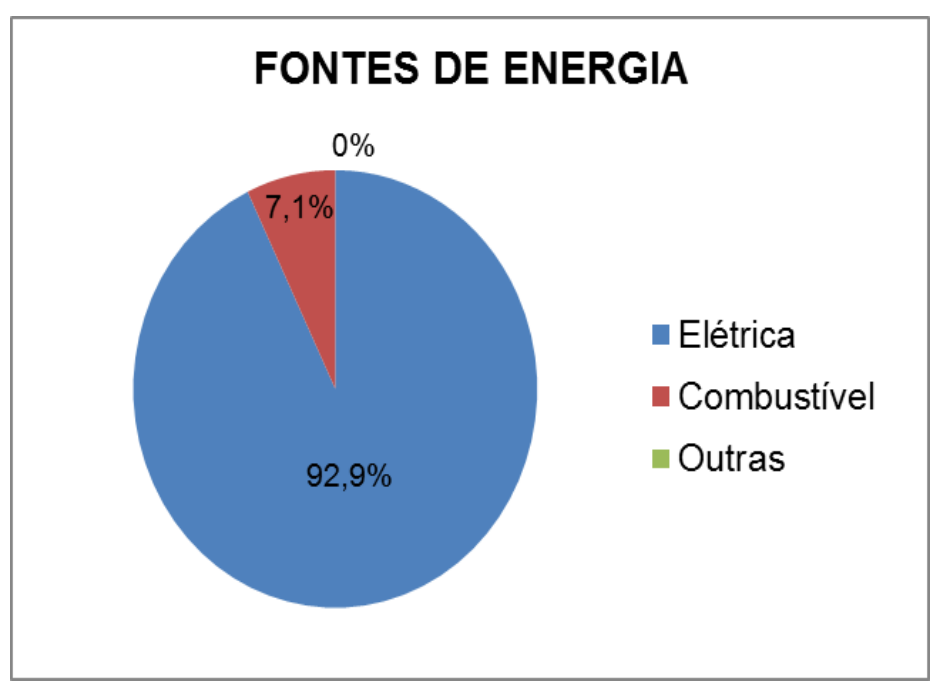

Figura 1. Fontes de energia. 
Com relação ao tempo de irrigação, para as hortaliças, o número de aplicações diárias varia entre uma e oito vezes com um tempo médio de 20 minutos cada. Para as demais culturas analisadas, o número de aplicações diárias é pequeno, porém o tempo de aplicação varia entre 1 e 12 horas. Em geral, o número de aplicações e o tempo das mesmas dependem do clima.

Para tais aplicações é necessário que a água seja de boa qualidade e que a fonte seja a mais confiável possível, afinal tratam-se de alimentos. A água quando não manejada corretamente, pode se tornar condutora de malefícios para as plantas. Entre as propriedades analisadas, 21 utilizam poços semiartesianos, 4 açudes, 1 rio e 2 outras fontes, no caso, uma propriedade com um córrego e a outra com uma mina (Figura 2).

Quanto ao consumo de água pelos sistemas, a pesquisa mostrou que muitos produtores têm baixo conhecimento quantitativo, pois poucos souberam informar a vazão de água da bomba e, consequentemente, não souberam dizer a quantidade de água aplicada na cultura, conhecimento esse, que se bem manejado, implica na oferta adequada de água às plantas, economia da mesma e redução de custos no processo produtivo.

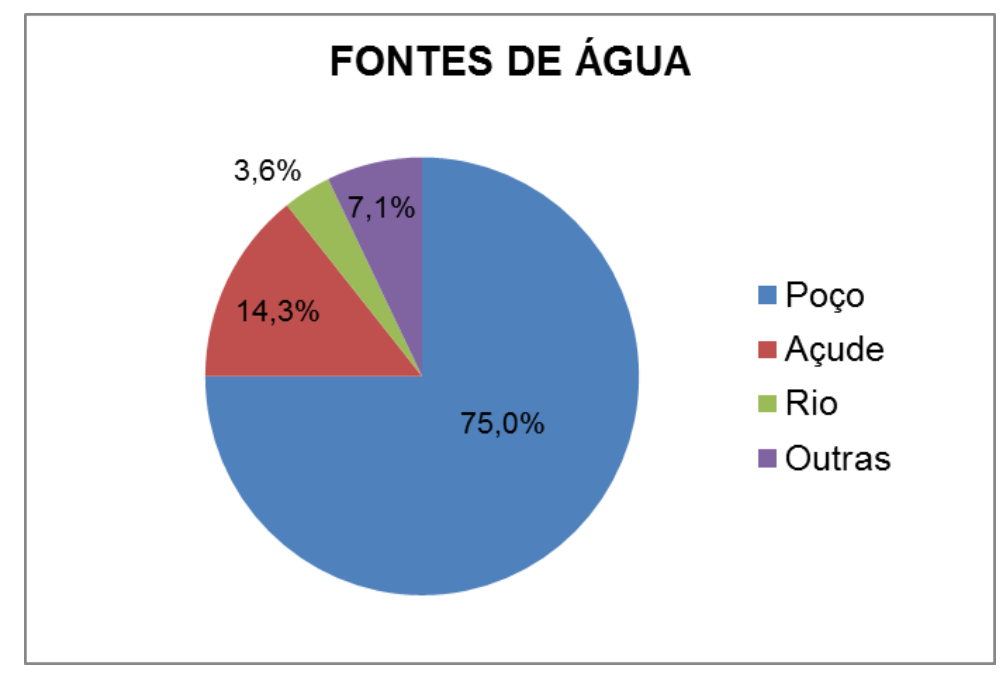

Figura 2. Fontes de água.

No que diz respeito à gestão do sistema, quando comparada produção sem irrigação com produção após a implantação de um sistema de irrigação, a pesquisa mostrou que poucos produtores detêm conhecimento e controle de informações para 
avaliar o incremento de produtividade e o incremento de renda, com uma ressalva quanto aos produtores de hortaliças, principalmente verduras, pois os mesmos alegam que não há produtividade sem irrigação neste tipo de cultura, logo não existem maneiras de comparar esses dois momentos distintos. Já em relação ao grau de satisfação dos produtores quanto aos sistemas de irrigação que se encontram instalados em suas propriedades, o resultado é bastante positivo, pois 23 produtores se dizem satisfeitos com o sistema adotado, 4 produtores parcialmente satisfeitos e 1 produtor insatisfeito com o seu sistema (Figura 3).

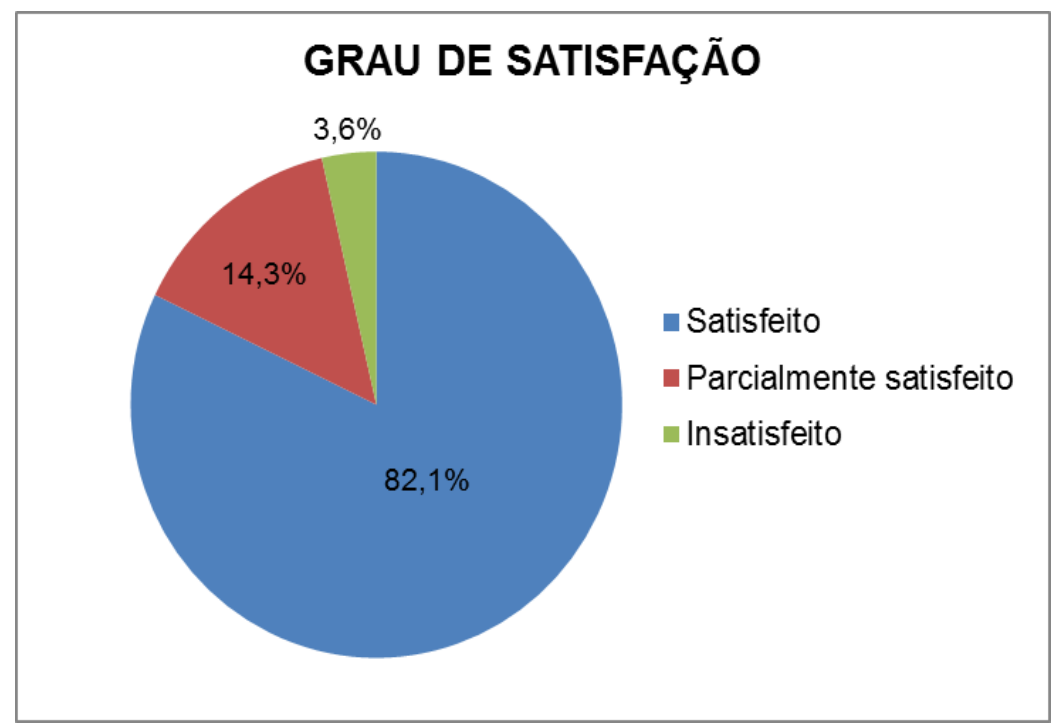

Figura 3. Grau de satisfação com o sistema adotado.

Quando questionados sobre outras informações relevantes ao uso de irrigação em suas propriedades, além do aumento de produtividade e aumento de renda, os produtores pontuaram benefícios tais como a possibilidade de sustentar suas famílias com uma pequena área de plantio, a permanência do homem no campo e a possibilidade de produzir em épocas de seca. Por outro lado, questões como custos de implantação e manutenção dos sistemas, custo elevado com energia elétrica, bem como dificuldades com reposição de peças desgastadas e/ou danificadas, são apontadas como entraves no processo produtivo quando se utiliza algum sistema de irrigação. Ainda lembraram que, mesmo sendo os responsáveis pelo suprimento de alimentos na atual discussão de uma 
futura escassez, o reconhecimento é discutível no que diz respeito do valor repassado ao produtor.

\section{CONCLUSÃO}

Neste trabalho buscou-se compreender por meio de pesquisa de campo a importância de sistemas de irrigação em propriedades rurais e o grau de satisfação dos produtores da região de Presidente Prudente em relação a esses sistemas.

A pesquisa realizada apontou que os produtores, em sua maioria, estão satisfeitos com a produtividade e rentabilidade advindas de culturas que fazem uso da irrigação e tal estudo deixa clara a importância desta técnica na região. No entanto, as entrevistas mostram que a maior parte dos produtores possui falta de conhecimento técnico, principalmente no que se refere à gestão dos sistemas de irrigação e seus custos. Tais conclusões sugerem um campo de atuação para profissionais do agronegócio e outros tipos de mão-de-obra especializada. Estes profissionais podem aplicar conceitos de gestão que tenham o potencial de atenuar os custos, aumentar as receitas e consequentemente ampliar as atividades do setor de produção rural que utilizam sistemas de irrigação na região.

A região estudada está inserida em um contexto considerado eminentemente agrícola, onde o agronegócio tem fundamental importância em sua economia. Portanto, autoridades e profissionais da área devem incentivar e fomentar essa técnica que garante a produção de alimentos por meio de qualificação e capacitação dos produtores que fazem uso da irrigação, pois a técnica gera mais empregos diretos e indiretos, melhora a renda dos produtores rurais e estimula a permanência do homem no campo. Não obstante, para que a agricultura irrigada assuma este papel na condução do desenvolvimento da região, faz-se necessário investimento em pesquisas com objetivo de adaptar as tecnologias da irrigação ao contexto agrícola regional. 


\section{REFERÊNCIAS}

MANN, P. S. Introdução a Estatística. 5aㅗ ed. LTC. Rio de Janeiro, 2006.

MANTOVANI, E. C. Aspectos Básicos da Irrigação de Sistemas Pressurizados. UFV. Montes Claros, 2008.

MANTOVANI, E. C.; BERNARDO, S.; PALARETTI, L. F. Irrigação: princípios e métodos. $3^{\mathfrak{a}}$ ed. UFV. Viçosa, 2009.

PIRES, R. M.; ARRUDA, F. B.; SAKAI, E.; CALHEIROS, R. O.; BRUNINI, O. Agricultura irrigada. Revista Tecnologia e Inovação Agropecuária - APTA. Campinas, 2008, vol.1, n. 1, p. 98-111.

PNRH - Plano Nacional de Recursos Hídricos. Panorama e estados dos recursos hídricos do Brasil. v.1. MMA. Brasília, 2006.

RICCI, S. R. Irrigação como alternativa de sustentabilidade agrícola e ambiental. Revista Multidisciplinar da UNIESP. Presidente Prudente, 2010, n. 10, p. 68-76.

RODRIGUES, G.; IRIAS, L. J. M. Considerações sobre os Impactos Ambientais da Agricultura Irrigada. Embrapa Meio Ambiente. Jaguariúna, 2004.

SOUZA, L. C. Águas e sua proteção. 1ª ed. Juruá. Curitiba, 2009.

TESTEZLAF, R.; MATSURA, E. E.; CARDOSO, J. L. Importância da irrigação no desenvolvimento do agronegócio. ABIMAQ/ CSEI/ UNICAMP. Campinas, 2002. 